\title{
Features of the spatial and temporal distribution of chlorophyll " a " and its relation to the water surface temperature by manifestations in the earth remote sensing data
}

\author{
Irma Martyn, Yaroslav Petrov*, Sergey Stepanov, and Artem Sidorenko \\ Russian State Hydrometeorological University, Voronezhskaya Street, 79, 192007 St. Petersburg, \\ Russian Federation
}

\begin{abstract}
An effective method for evaluating chlorophyll "a" is remote sensing in the optical range by satellite spectroradiometers. To study the concentration of chlorophyll "a" in the bio-productive regions of the ocean, we used data from the MODIS-Aqua scanner of the NASA GIOVANNI system, which provides access to satellite data archives at the same time as tools for their processing and analysis. The variability of the chlorophyll "a" concentration in surface waters may indicate the state of water productivity. The paper considers the temporal and spatial variability of chlorophyll "a" concentration and water surface temperature from satellite data and the influence of water surface temperature on this variability in the Gulf of Alaska and in the area of the Peruvian upwelling. As a result, a direct relationship between changes in the concentration of chlorophyll "a" and the water surface temperature was revealed. It is possible to assess the bio-productivity depending on the variability of the concentration of chlorophyll "a".
\end{abstract}

\section{Introduction}

The main producer of organic matter in the seas and oceans is phytoplankton. The complex chemical compound chlorophyll, which is part of phytoplankton cells, is the main apparatus that provides the process of photosynthesis. In plant cells, there are several varieties of chlorophyll: chlorophyll "a" and "b" in higher plants, chlorophyll "b" and "C" in lower plants [1]. Only chlorophyll "a" is required for the mechanism of biochemical synthesis. The content of chlorophyll "a" in marine phytoplankton is an important characteristic of assessing the primary biological productivity of water: a natural relationship between its quantity and the amount of phytoplankton production, as well as the ability to calculate production from known concentrations of chlorophyll "a" and illumination on the horizons [2]. Some authors note a direct proportional relationship between chlorophyll "a" and the value of primary production. The primary production produced by phytoplankton during photosynthesis determines the development of the rest of the living marine world [3].

\footnotetext{
*Corresponding author: yaroslav.petrov025@gmail.com
} 
The object of the study was the concentration of chlorophyll "a" in the bioproductivity area of the Gulf of Alaska and the area of the Peruvian upwelling.

The aim of this work is to study the distribution of chlorophyll "a" and its relationship with the water surface temperature off the West coast of South America and in the Gulf of Alaska.

\section{Materials and methods}

The Giovanni system is designed for online visualization and analysis of satellite data. The list of data provided by this system can be found at the following address http://disc.sci.gsfc.nasa.gov/giovanni. The Giovanni system allows you to get data for analysis from multispectral scanning systems SeaWiFS and Terra, Aqua/MODIS with a spatial resolution of 4 and $9 \mathrm{~km}$ (obtained from data with an initial spatial resolution of 1 $\mathrm{km}$ ) [4]. This data is obtained by converting the results of a daily survey of the Earth's surface in files to monthly averages for each square of $4 \times 4 \times 9 \mathrm{~km}$ in the world's oceans. The values of the color index of ocean waters are calculated from the brightness values in the blue and green zones, and the corresponding values of the chlorophyll "a" concentration are calculated based on the established in situ patterns. Using the Giovanni system, you can create - averaged cartographic images (Area Plot), - graphs of the dependence of the parameter (chlorophyll concentration) on time (Time Plot) for the selected study area and the specified time interval), - space-time Hovmoller diagrams, which are used to visualize data and detect changes, both in time and space. You can create animations for map images $[5,6]$.

\section{Analysis of results}

Observation of chlorophyll suggests that we can determine the amount of phytoplankton in the study area. Marine phytoplankton is of considerable interest due to its widespread distribution and great importance in the biological productivity of the world's oceans. It consists of autotrophic (photosynthetic), heterotrophic (using dissolved organic matter) and phagotrophic (feeding on individual particles) organisms [7]. Autotrophic organisms, which have chlorophyll, often predominate in number and are important producers of primary organic products synthesized during photosynthesis.

Off the coasts of Chile and Peru (Fig. 1), during the cold season, the amount of chlorophyll increases from the open ocean to the coast from 0.2 to $30 \mathrm{mg} / \mathrm{m} 3$, respectively (Fig. 2,4,6,8). The temperature at this time is almost uniform, in the southern part of the study area and near the coast of Peru, the temperature is higher than in the entire water area, and reaches $18^{\circ} \mathrm{C}$. It is also observed in the very South, near the coast of Chile, the lowest temperature is about $12^{\circ} \mathrm{C}$ (Fig. 3,5,7,9). By 2020, the area of high concentration of chlorophyll "a" has decreased near the western coast of South America (Fig. 6.8), which is associated with an increase in the area of heated waters in the north of the study area (Fig. 7.9)

During the warm season, the region shows the greatest variation in chlorophyll values than during the cold season, but at the same time, the area with the highest chlorophyll value has increased, especially off the coast of Peru. The temperature remained with the same distribution as in the cold period, only the temperature values are higher by $2^{\circ} \mathrm{C}$. When the temperature increases, chlorophyll increases, and the warm environment has a good effect on photosynthesis and the development of various organisms. 


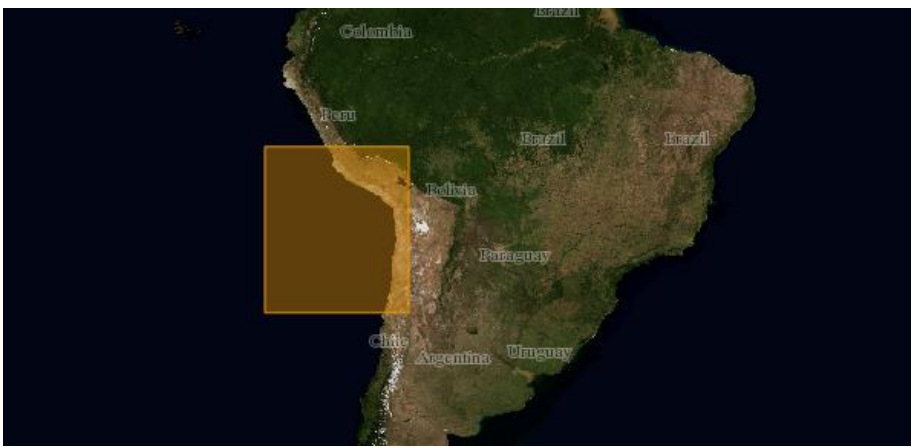

Fig. 1. Study area. District of the Peruvian upwelling

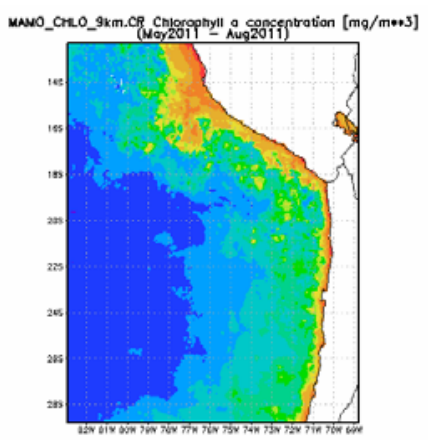

Fig. 2. Spatial distribution of chlorophyll "a" concentration for the period may-August 2011

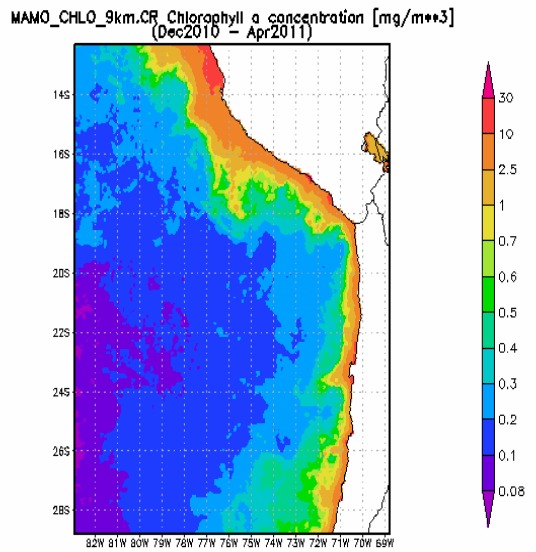

Fig. 4. Spatial distribution of chlorophyll "a" concentration for the period December 2010-April 2011

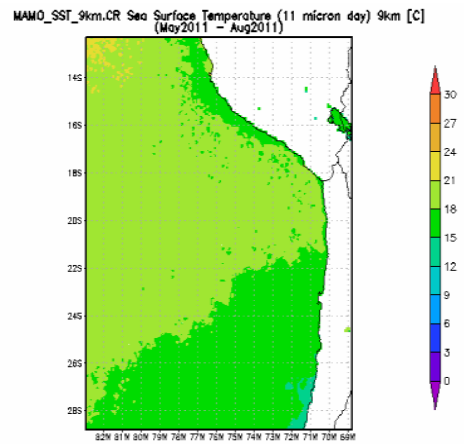

Fig. 3. Spatial distribution of water surface temperature for the period may-August 2011

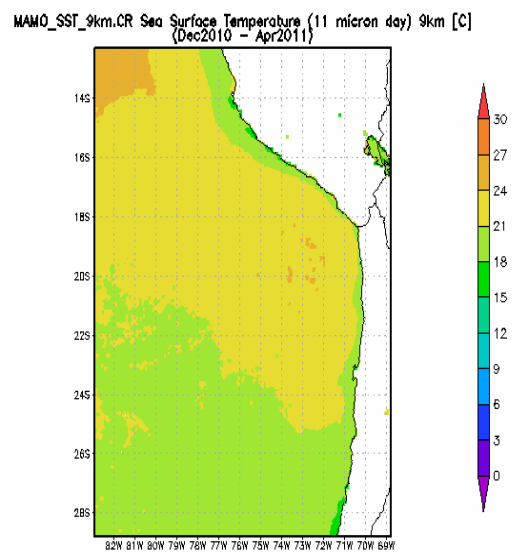

Fig. 5. Spatial distribution of water surface temperature for the period December 2010April 2011 


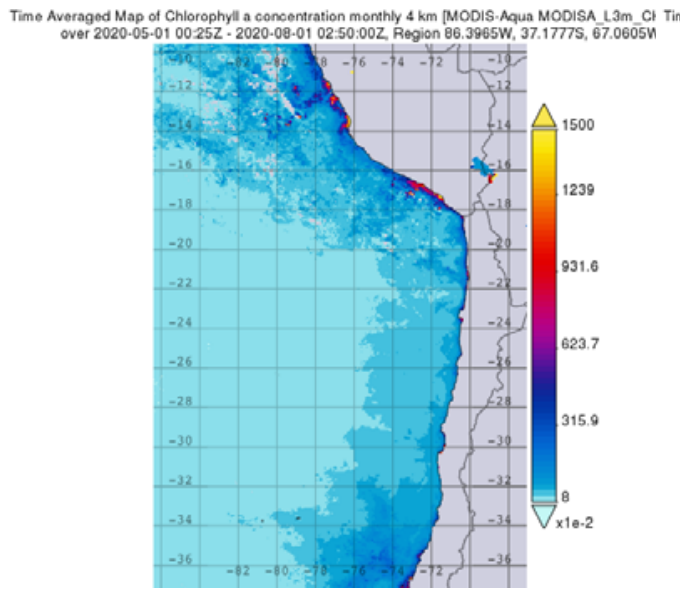

Fig. 6. Spatial distribution of chlorophyll "a" concentration for the period may-August 2020

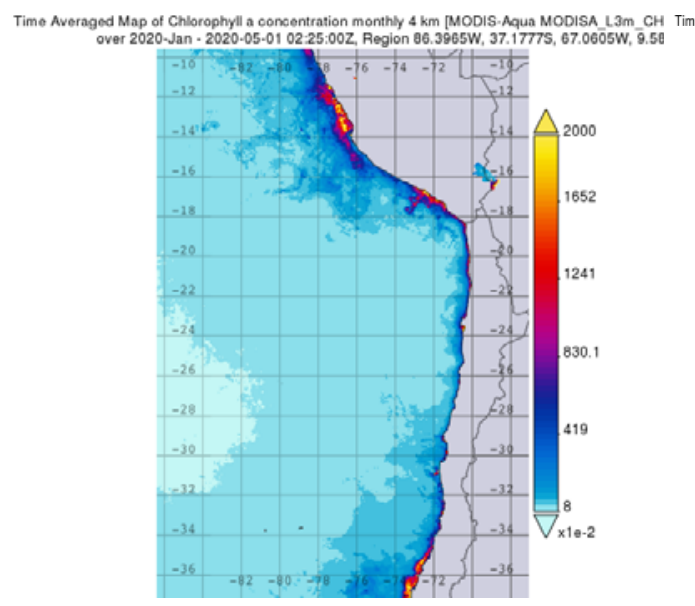

Fig. 8. Spatial distribution of chlorophyll "a" concentration for the period December 2019-April 2020

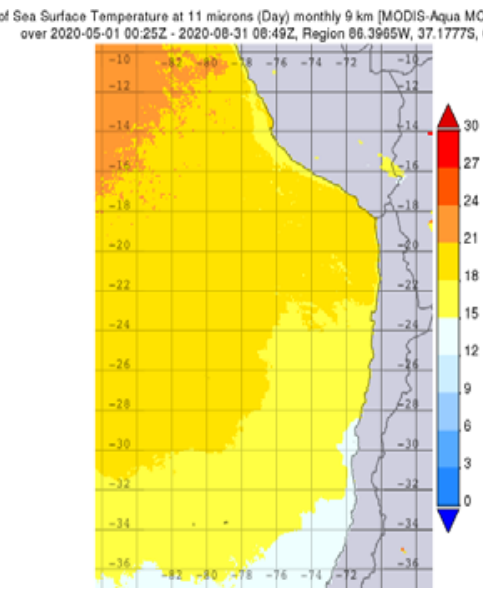

Fig. 7. Spatial distribution of water surface temperature for the period may-August 2020

In the diagram describing the annual flow of chlorophyll (Fig. 10,12), it is noted that in each month the amount of chlorophyll is almost constant, and increases towards the coast. The temperature has a clear course (Fig. 11,13). From June to November, the temperature is the same everywhere and the lowest for the whole year, and it gradually increases by January and December, while the waters near the coast become warmer than in the open ocean. From April to February, the greatest difference between the temperature near the coast and the open ocean, at the coast the maximum for the whole year is up to $30^{\circ} \mathrm{C}$. In low latitudes, the development of phytoplankton is more often associated with the rise of waters rich in nutrient salts from the bottom. And usually the diversity of living organisms becomes poorer when moving away from the coast. 


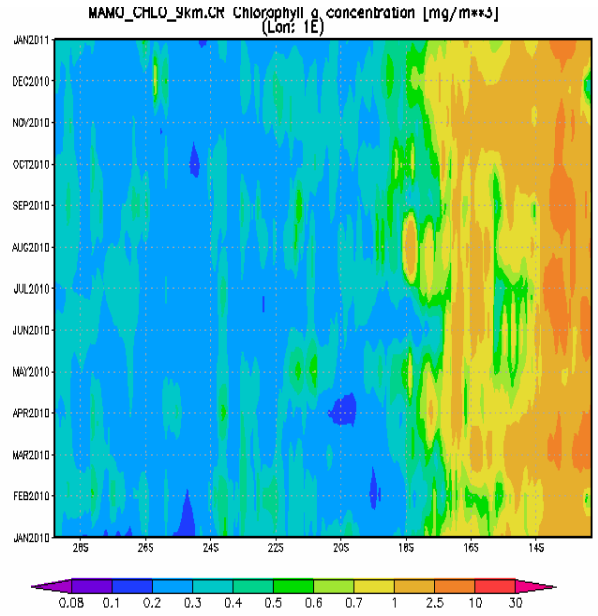

Fig. 10. The distribution graph of the concentration of chlorophyll "a" for the period January 2010January 2011

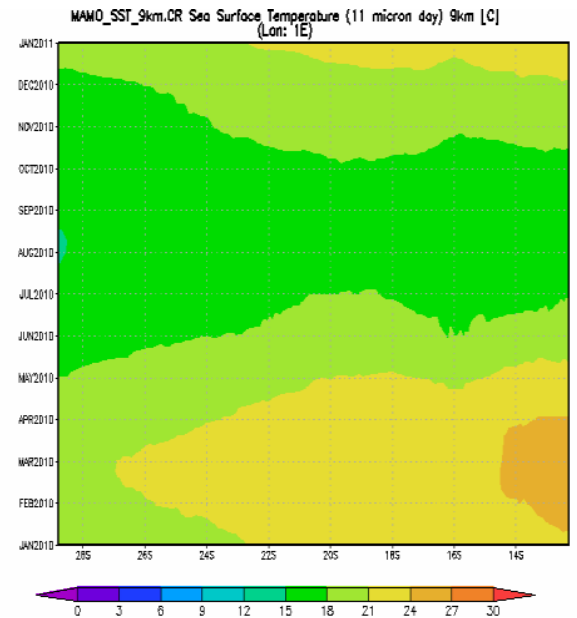

Fig. 11. Water surface temperature distribution chart for the period January 2010-January 2011

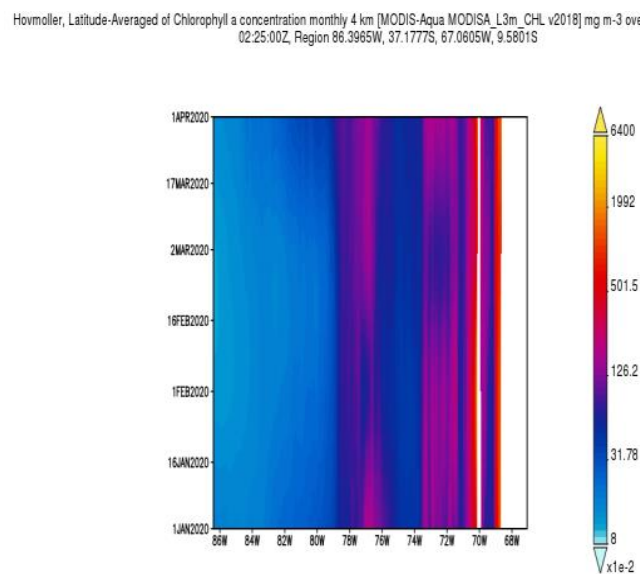

Fig. 12. The distribution graph of the concentration of chlorophyll "a" for the period January 2020April 2020 a Suface Temperature at 11 microns (Day) monthly $9 \mathrm{~km}$ [MODIS.Aqua MODISA_L3m_SST_Monthly__km vR2019.0] C over

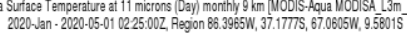

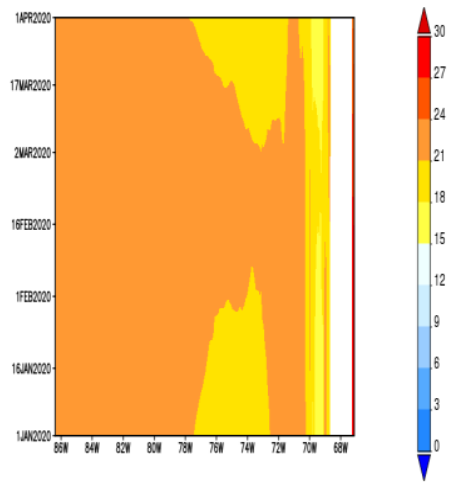

In another area of research in the Gulf of Alaska (Fig.14) in the warm period of the year, chlorophyll is highest near the coast, especially in the Western part varies between $0.4-10 \mathrm{mg} / \mathrm{m} 3$ (Fig.15). The temperature in the Bay area as almost everywhere uniform 9$12^{\circ} \mathrm{C}$, changes only near the shore in the Meridian direction from the East about $12-15^{\circ} \mathrm{C}$, in the West is $6-9^{\circ} \mathrm{C}$ (Fig.16).

During the cold period, the amount of chlorophyll becomes significantly less (Fig. 17), and here the amount of chlorophyll $0.7 \mathrm{mg} / \mathrm{m} 3$ or higher is distributed over an area of about half of the studied water area. At the same time, it can be noted that if during the warm period more chlorophyll was observed near the West coast, then during the cold period in this area, its amount is approximately uniform along the entire coast. The temperature becomes even more uniform throughout the entire water area, only on the Western coast (especially in small bays) the temperature is lower and falls below $0^{\circ} \mathrm{C}$ (Fig. 18). In 2020, 
off the coast of Alaska, the area of high concentration of chlorophyll "a" decreased (Fig. $15,17,19,21$ ), which is associated with an increase in water temperature (Fig. 16,18,20,22).

From this we can conclude that the lower the temperature, the more chlorophyll there will be.

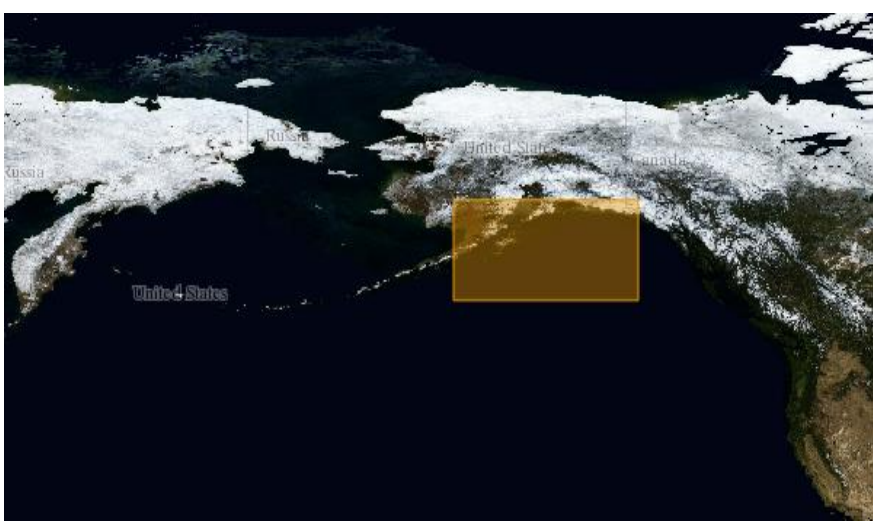

Fig. 14. The area of study. Gulf of Alaska

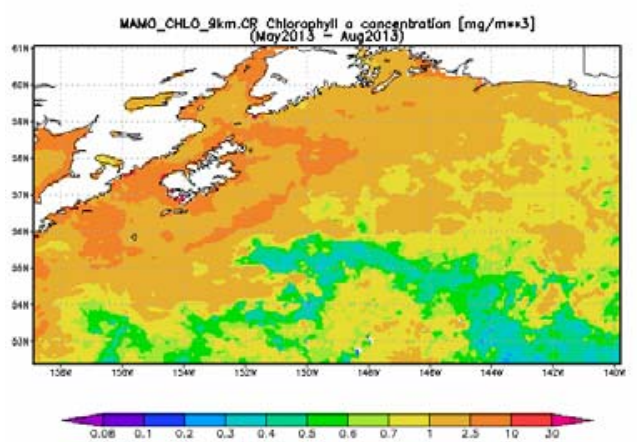

Fig. 15. Spatial distribution of chlorophyll "a" concentration for the period may-August 2013
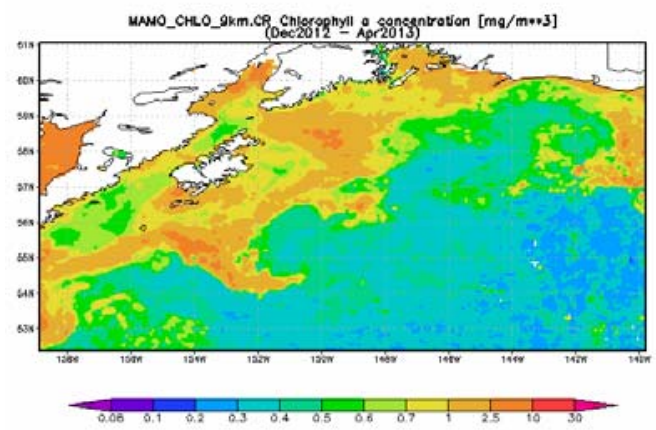

Fig. 17. Spatial distribution of chlorophyll "a" concentration for the period December 2012April 2013

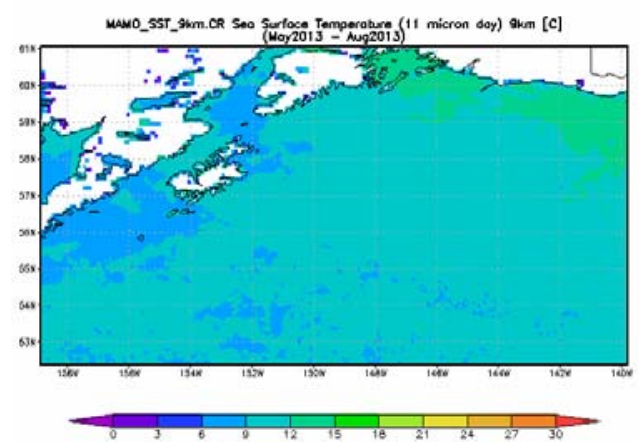

Fig. 16. Spatial distribution of water surface temperature for the period may-August 2013

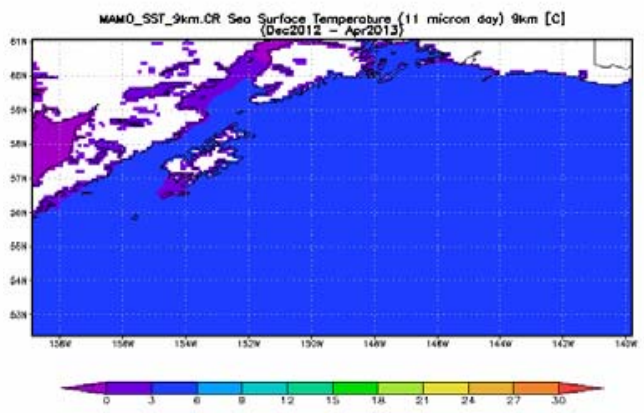

Fig. 18. Spatial distribution of water surface temperature for the period December 2012-April 2013 


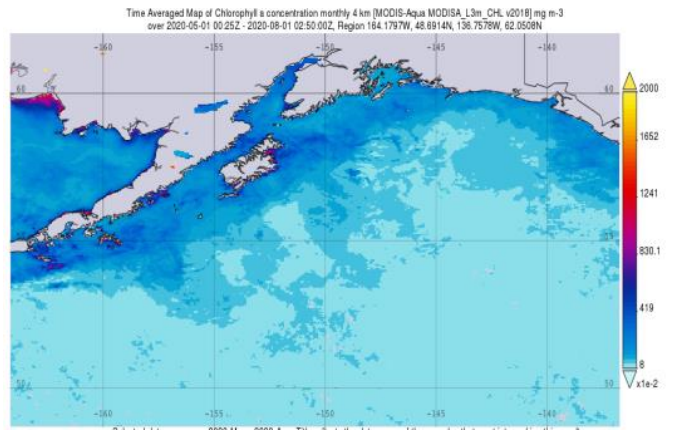

Fig. 19. Spatial distribution of chlorophyll "a" concentration for the period may-August 2020

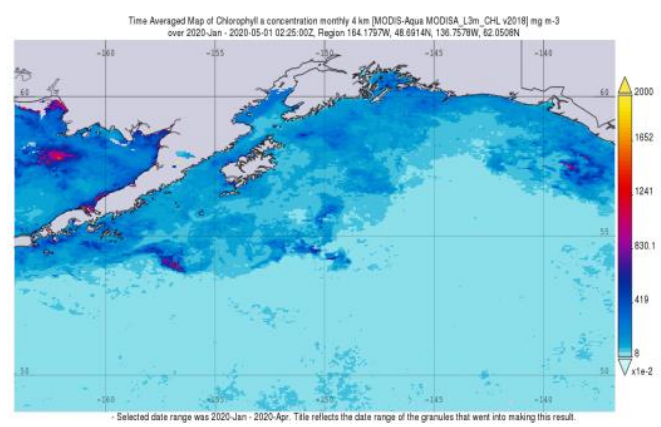

Fig. 21. Spatial distribution of chlorophyll "a" concentration for the period December 2019April 2020

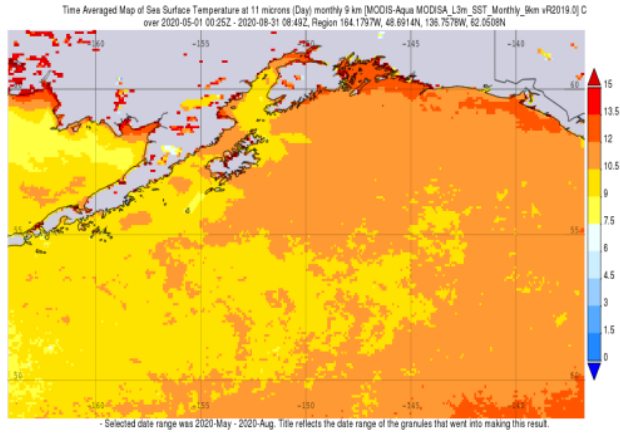

Fig. 20. Spatial distribution of water surface temperature for the period may-August 2020

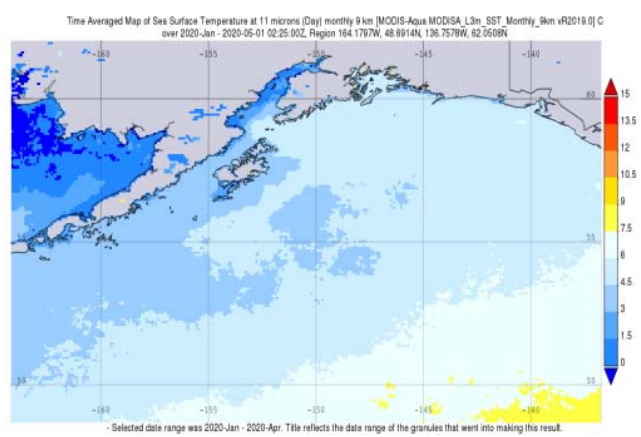

Fig. 22. Spatial distribution of water surface temperature for the period December 2019-April 2020

The diagram clearly shows the course of change in chlorophyll (Fig. 23,25), it is least in winter, reaches its peak in may, and is also of great importance in the summer months. As a rule, in high latitudes, phytoplankton (associated with the value of chlorophyll) develops in the spring, because during this period the flow of solar radiation increases and the water temperature increases, convective mixing develops. Increases towards the coast, but in may during the peak, the maximum is observed not near the coast, but further from it. As mentioned above, the diversity of living organisms becomes poorer when moving away from the coast, this character is due to the supply of solar energy, nutrients, etc.

The temperature is distributed almost uniformly, in winter the minimum temperature (below 0) is observed near the coast and further from it, and in summer the highest temperature is up to $15^{\circ} \mathrm{C}$ also near the coast (Fig. 24,26). 


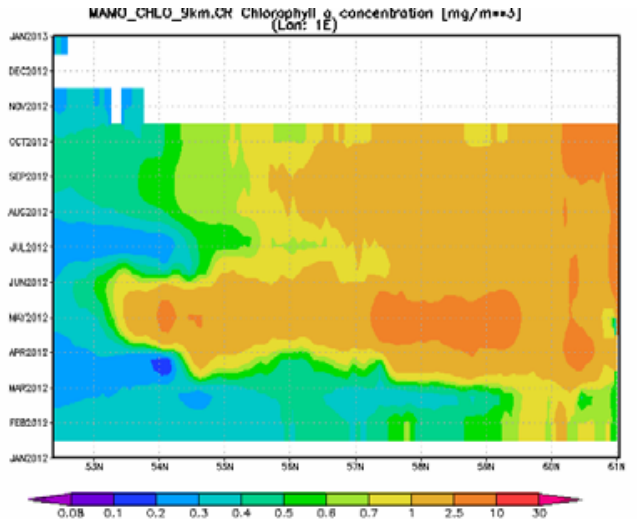

Fig. 23. Spatial distribution of chlorophyll "a" concentration for the period January 2012-January 2013

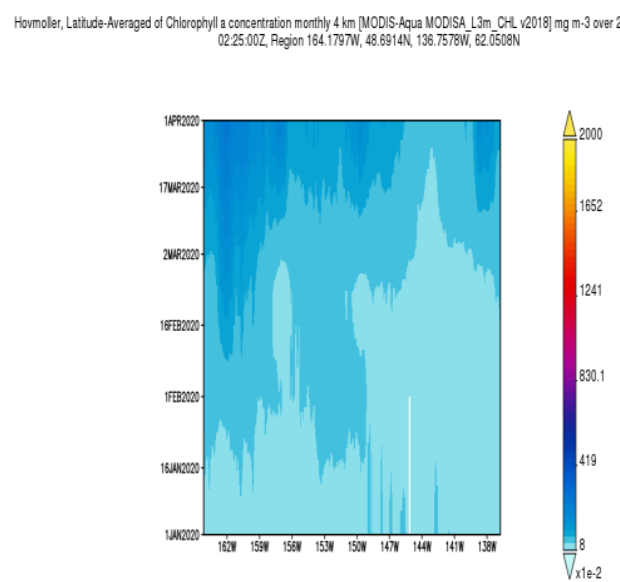

-Selected date range was 2020 Van - 2020-Apr. Thile reflects the date range of the granules that went into making this resu

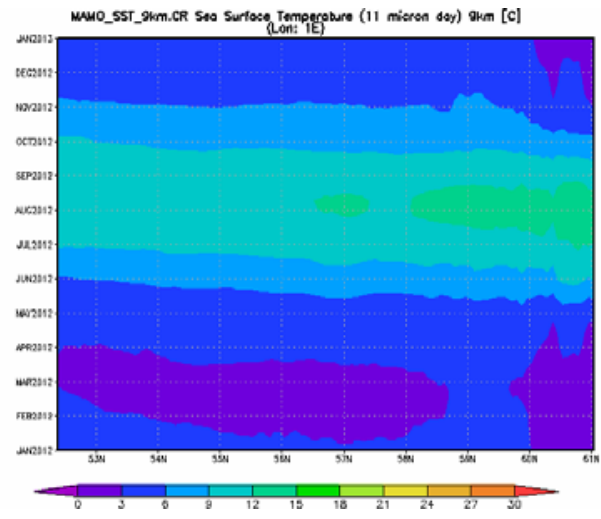

Fig. 24. Spatial distribution of water temperature for the period January 2012January 2013
Fig. 25. Spatial distribution of chlorophyll "a" concentration for the period January 2020-April 2020
Fig. 26. Spatial distribution of water temperature for the period January 2020-April 2020

\section{Conclusions}

Thus, it was found that changes in chlorophyll "a" directly depend on changes in temperature, which also affects many other components of natural and technical systems [810]. Observation of chlorophyll suggests that we can judge the amount of phytoplankton in the study area and, consequently, the bioproductivity of the area.

In high latitudes, phytoplankton (associated with the value of chlorophyll) develops in the spring, because during this period, the flow of solar radiation increases and the water temperature increases, and convective mixing develops.

In low latitudes, the development of phytoplankton is more often associated with the rise of nutrient-rich waters from the bottom.

In 2020, compared to 2011, an increase in the area with warm waters is noted, which led to a decrease in the concentration of chlorophyll "a" and the productivity of waters of the studied water areas. 


\section{References}

1. M.A. Pavlova, E.B. Makarevich, Advances in Contemporary Natural Science, 56 (2011)

2. P.A. Salyuk, I.E. Stepochkin, I.A. Golik, O.A. Bukin, A.N. Pavlov, A.I. Aleksanin, Exploration of the Earth from Space, 3, 45 (2013)

3. G.I. Semina, Science, 239 (1974)

4. K.S. Shifrin, Gidrometeoizdat (1983)

5. V.I. Burenkov, O.V. Kopelevich, S.V. Sheberstov, S.V. Ershova, M.A. Evdoshenko, The Eastern Mediterranean as Contrasting Ecosystems, 313 (1999)

6. H. Kim, S. Yoo, I. Oh, J. of Marine Systems, 67, 205 (2007)

7. K. Yamada, J. Ishizaka, S. Yoo, H. Kim, S. Chiba, Progress in Oceanography, 61, 193 (2004)

8. I. Martyn, Y. Petrov, S. Stepanov, A. Sidorenko, IOP Conference Series: Earth and Environmental Science, 539, 012198

9. E. Istomin, Y. Petrov, S. Stepanov, A. Sidorenko, I. Martyn, IOP Conference Series: Earth and Environmental Science, 507, 012006

10. A. Sidorenko, S. Stepanov, Y. Petrov, I. Martyn, IOP Conference Series: Earth and Environmental Science, 539, 012128 